\title{
PSYCHOLOGICAL SKILLS OF TALANTED ATHLETES IN INDIVIDUAL SPORTS IN LATVIA
}

\author{
Dace Eikena
}

National Sports Academy "Vassil Levski”, Sofia, Bulgaria

\begin{abstract}
Ability to competing at the highest level requires the athlete's endurance, tactical and technical preparedness and mental toughness. There are structured and systematic psychological preparation is neccessery especially when the athlete is young. It is important to find weakest skill and offer well targeted program for its improvement. And essential edge is to show "a full picture" and to offer athletes insight into factors that influence the development of a successful sports career. Athletes psychological skills developement is a main part in psychological preparation and the way to reach the elite level.

This study concentrates on athletes that have been identified as talented and have first successful performing experience in international (European and World Championships) competitions in their age. There are examine 53 talented athletes representing various summer sports in Latvia. In this study used PSIS R5 questionnaire form adapted in Latvia. There are six basic psychological skills are measure: motivation, self-confidence, mental preparation, anxiety control, concentration and team emphasis. The results obtained are analyzed and compared to determine individual characteristics and gender differences. The study results showed psychological skills differences between gender. The strongest skills are motivation, and team emphasis for both males and females, but males have additional strong psychological skill self-confidence. The main improvement areas are similar, i.e. anxiety control, concentration and mental preparation for all athletes and additional weak skill for female is self-confidence in this study. PSIS R5 questionnaire is a suitable tool for diagnosing athletes basic psychological skills levels. This study findings can be used as a starting point for developing well-targeted athletes psychological skills training programs in Latvia.
\end{abstract}

Key words: athletes, psychological skills, gender, PSIS R5 questionnaire

\section{INTRODUCTION}

An elite athlete is a rare combination of talent, hard work and right psychological profile. Often the difference between the good and the elite is the mental qualities of the athletes. The focus of this study is young successful athletes and possible psychological skill differences by gender.

This study concentrates on athletes that have been identified as talanted and have first successeful performing in international level competitions in their age. It is important to assist athletes especially young in reaching elite level and to gain insight into factors that influence the development of a successful sports career. There is a range of physical and mental components that contribute to successful performance in sports. Each sport and activity requires a specific set of these skills. Being successful in one sport does not necessarily make you successful in another, as success requires a whole range of factors to come together and interact in the right way. Performance can be thought of as a noun or a verb. As a noun, it describes a discrete event where a performer (or performers) show- cases a specific set of developed knowledge, skills, and abilities. Performance can also be a verb, which then describes the process of carrying out a plan of action for the execution of knowledge, skills, and abilities during a performance event. Thus, performance means using knowledge, skills, or abilities, as distinguished from merely possessing them. As Aoyagi and Portenga (2010) state, "successful performance requires both the development and mastery of knowledge, skills, or abilities and the capability to consistently and reliably deliver (i.e., perform) knowledge, skills, and abilities at the time of performance"

Psychological skills are important in gaining the winning edge in particular in the area of competitive anxiety. Sports psychologists interest has focused on techniques that athletes can use in the competitive situations to maintain control and optimise their performance. Once learned, these techniques allow the athlete to relax and to focus his/her attention in a positive manner on the task of preparing for and participating in competition. For example, concentration is the mental quali- 
ty to focus on the task in hand. If the athlete lacks concentration, then their athletic abilities will not be effectively or efficiently applied to the task. But confidence is results from the comparison an athlete makes between the goal and their ability. The athlete will have self-confidence if they believe they can achieve their goal. (Comes back to a quote of mine - „You only achieve what you believe"). When an athlete has self-confidence they will tend to: persevere even when things are not going to plan, show enthusiasm, be positive in their approach and take their share of the responsibility in success and fail. Athletes will develop a routine for competition. If these routines are appropriately structured, then they can prove a useful aid to concentration. Identifying when an athlete feels a particular emotion and understanding the reason for the feelings is an important stage of helping an athlete gain emotional control. An athletes ability to maintain control of their emotions in the face of adversity and remain positive is essential to successful performance.

A competitive mindset is advantageous to successfully compete in sports. Researchers already supported association between psychological skills and sports performance in general. In an attempt to differentiate between successful and non successful competitors (to distinguish skill position, or gender, to ascertain the effects of training, or develop a model of the psychological profile, neccessery for optimale performance, attention is given toward psychological skills relevant to competition. Mahoney, Gabriel \& Perkins(1987) developed an instrument that assesses a board range of psychological skills possessed by athletes and is sports specific. The PSIS-R5 assess mental skill characteristics relevant to exceptional athletic performance. The differences exist in psychological skills between individual and team sports, and between genders. Many researchers made modifications and own versions of PSIS-R5. Applied the Dutch Yous version researchers found that psychological skills distinguished between more and less successful talented athletes especially in females. In general, the difference in psychological profiles between men and women and between team and individual sports athletes. For discrimination of elite athletes and sub elite young athletes motivation and mental preparation were useful indicator that are independent of gender and type of sport.

Other researchers found that among physical, tech- nical and mental characteristics, mental readiness provided the only statistically significant link with final Olympic ranking of Canadian Olympians. In other study was find no differences in psychological skills between top ranked, middle ranked and bottom ranked female world-ranked tennis players.

It seems interesting to look at the psychological skills of talanted and elite athletes locally in Latvia.

\section{METHOD}

The goal of the study is to find differences in psychological skills among successful athletes in individual summer sports and compare by gender.

\section{Participants}

Participants of this investigation are 53 talented athletes in individual sports. They all perform in 11 different summer individual sports such as the tennis, BMX, athletics, canoe, kayaking, rowing, karate, beach volleyball, swimming and some others. They participate Europian and World level competitions in their age and few of them are candidates to take part in Olympic games 2020. Athletes are in age from 15 to 31 years, the athletes mean age is $18,87(\mathrm{SD}=3,6)(\mathrm{tab} .1)$. There are $57 \%$ males and $43 \%$ females, $13 \%$ left-handed athletes and $87 \%$ right-handed athletes, and no ambidextrous athletes.

\section{Measures}

For psychological traits discovering in this study used the Psychological Skills Inventory for Sports (PSIS R5) questionnaire built by Mahoney et al. (1987) and adapted in Latvia. PSIS R5 determines multiple psychological skills. The PSIS-R5 test has 45 items. A total 45 items was divided into six skills scales consisting of motivation ( 7 items), self-confidence (9 items), anxiety control (10 items), mental preparation (6 items), and concentration (6 items), and team emphasis skills (7 items). The test items evaluated in the Likert scale of five grades (from 0 to 4), in which Mahoney reports internal consistency by the Spearman Brown coefficient of 0,724 (preferably greater than 0,7 ), the Gutman part confidence coefficient is 0,707 .

The adaptation of PSIS - R5 in Latvia has been taking place since 1997, when Latvian researchers approached the Intercultural Study Test Adaptation, led by Professor C.Mahoney of the London Roamhampton Institute. Athletes from Ireland, England, 
the Czech Republic, Greece, the USA and Latvia participate. Data was grouped based on the nationality and gender of the athlete.

On the scale of anxiety control $\mathrm{M}=57,8$ ( $\mathrm{SD}=$ $12,4)$; on the scale concentration $\mathrm{M}=58,3$ ( $\mathrm{SD}=$ 14,7 ); on the scale self-confidence $\mathrm{M}=59,3$ ( $\mathrm{SD}=$ $17,8)$; on the scale of mental preparation $M=46,7$ $(\mathrm{SD}=11,4)$; on the scale of motivation $\mathrm{M}=57,2$ ( $\mathrm{SD}=16,8)$; on the scale of team emphasis $\mathrm{M}=61,8$ $(\mathrm{SD}=11,7)$; the mean of the whole test scales $\mathrm{M}=$ $58,1(\mathrm{SD}=9,1)$.

The Pearson correlation coefficient was applied to determine mutual correlations between the scales. In Latvian case the Pearson correlation coefficient between the test scales does not exceed 0,56. the correlation between PSIS R5 concentration, anxiety control and self-confidence scales is moderate $\mathrm{r}=0,4-0,7$, but between the other scales negligible $\mathrm{r}=0-0,3$, and so it can be assumed that each scale measures a relatively different characteristic.

The reliability indices of the internal consistency of PSIS R5 questionnaires are as follows: Cronbach alpha coefficient 0,79 , correlation between parts 0,67 , Spearman Brown coefficient 0.80, and Guttman-Rulon confidence coefficient 0,77 . In Latvian study this coefficients are higher than in original one has (Mahoney .J., Gabriel T.J., Perkins T.S., 1987) Cronbach's alpha coefficient 0,64, Spearman Brown coefficient 0,72, and Gutman's confidence coefficient 0,70 .

Latvian researchers (in 1997 study) suggest to improve this scale in the future by revising the wording of the questions and re-establishing the causal relationship between them. The test scales of the reliability variables are varied, because the range of values of reliability ratios is wide; the correlation between the parts is from - 0,07 to 0,68. Spearman Brown coefficient from - 0,15 to 0,81 , Gutman confidence coefficient from $-0,15$ to 0,79 .

Mahoney (1998) has found that elite athletes have clear goals for each day, less anxiety, greater selfesteem, higher motivation and better control strategies. The test is suitable for determining the psychological skills of athletes of different levels. The test explores cognitive strategies and success in sport.

\section{RESULTS}

On the scale Anxiety Control the mean for all participants (table 1$)$ is $55,58(\mathrm{SD}=11,65)$ and it is the weakest skill at all, for males $\mathrm{M}=56,33(\mathrm{SD}=8,50$,) for females $M=54,13(S D=14,92)$.

Table 1. Distribution of mean scores in PSIS r5 scales by gender

\begin{tabular}{|c|c|c|c|c|c|c|c|}
\hline \multicolumn{2}{|c|}{ Gender } & $\begin{array}{l}\text { Anxiety } \\
\text { control }\end{array}$ & Concentration & $\begin{array}{c}\text { Self- } \\
\text { confidence }\end{array}$ & $\begin{array}{c}\text { Mental } \\
\text { preparation }\end{array}$ & Motivation & $\begin{array}{c}\text { Team } \\
\text { emphasis }\end{array}$ \\
\hline \multirow{3}{*}{1} & Mean & 56,33 & 56,38 & 61,67 & 58,61 & 71,43 & 64,30 \\
\hline & $\mathrm{N}$ & 30,00 & 30,00 & 30,00 & 30,00 & 30,00 & 30,00 \\
\hline & SD & 8,50 & 13,79 & 10,76 & 12,52 & 10,58 & 12,44 \\
\hline \multirow{3}{*}{2} & Mean & 54,13 & 59,05 & 58,45 & 54,67 & 72,02 & 63,01 \\
\hline & $\mathrm{N}$ & 23,00 & 23,00 & 23,00 & 23,00 & 23,00 & 23,00 \\
\hline & SD & 14,92 & 16,47 & 12,97 & 11,74 & 19,61 & 13,56 \\
\hline \multirow{3}{*}{ Total } & Mean & 55,38 & 57,54 & 60,27 & 56,90 & 71,69 & 63,73 \\
\hline & $\mathrm{N}$ & 53,00 & 53,00 & 53,00 & 53,00 & 53,00 & 53,00 \\
\hline & SD & 11,65 & 14,92 & 11,76 & 12,23 & 15,01 & 12,83 \\
\hline
\end{tabular}

On the motivation skills scale's the mean for all $=19,61)$. On the concentration skills the mean for participants is $71,69(\mathrm{SD}=15,01)$ and it is the all participants is $57,54(\mathrm{SD}=14,92), \mathrm{M}=56,38$ strongest skill at all. For males in this skills $M=(S D=13,79)$ for males and for females $M=59,05$ $71,43(\mathrm{SD}=10,58)$ and for females $\mathrm{M}=72,02(\mathrm{SD} \quad(\mathrm{SD}=16,47)$. 
On the self-confidence skills the mean for all par- $\quad M=58,61(S D=12,52)$, for females $M=54,67$ ( $S D$ ticipants is $60,27(\mathrm{SD}=11,76)$, for males $\mathrm{M}=61,67=11,74)$. On the team emphasis skills the mean $(\mathrm{SD}=10,76)$ and for females $\mathrm{M}=58,45$ ( $\mathrm{SD}=$ for all participants is $63,73(\mathrm{SD}=12,83)$, for males $12,97)$. On the mental preparation skills the mean $M=64,3(S D=12,44)$ and for females $M=63,01$ for all participants is $56,9(\mathrm{SD}=12,23)$, for males $\quad(\mathrm{SD}=13,56)$.

Table 2. Results from correlations analasis

\begin{tabular}{|c|c|c|c|c|c|c|c|c|}
\hline & & AC & C & SC & MP & $\mathbf{M}$ & TE & Average \\
\hline \multirow{6}{*}{$\begin{array}{l}\text { Spearman's } \\
\text { Correlation } \\
\text { Coefficient }\end{array}$} & $\mathrm{AC}$ & & ,288* &, $360 * *$ & & & &, $454 * *$ \\
\hline & C & ,288* & & ,274* & &, $356 * *$ & &, $635 * *$ \\
\hline & $\mathrm{SC}$ &, $360 * *$ & ,274* & & &, $402 * *$ & &, $688 * *$ \\
\hline & MP & & & & & & &, $257 *$ \\
\hline & M & &, $356^{* *}$ &, $402 * *$ & & & &, $609 * *$ \\
\hline & TE & & & & & & &, $361 * *$ \\
\hline
\end{tabular}

${ }^{*}$. Correlation is significant at the 0.05 level (1-tailed) ${ }^{* *}$. Correlation is significant at the 0.01 level (1-tailed).

There are significant correlation between all ath- with investing in a systematic job that is directly letes psychological skills average scores mean and relevant to the athlete individual skills profile. In self confidence $r=, 688^{\star *}$, concentration $r=, 635^{\star *}$, situations where educational work is taking place in motivation $r=, 609^{* *}$. There are high corelation be- sports schools or clubs, it is important to be aware tween motivation and concentration $\mathrm{r}=, 356^{* *}$; and of common trends in psyhological skills across genbetween motivation and self-confidence $r=, 402^{* *}$. der, age and sport.

It is necessary to identify weakest skills and start

Table 3. Correlations between the scales average scores for males

\begin{tabular}{|c|c|c|c|c|c|c|c|c|c|}
\hline & & & AC & $\mathrm{C}$ & SC & MP & $\mathbf{M}$ & TE & Average \\
\hline \multirow{7}{*}{ Spearman's rho } & Male & $\mathrm{N}$ & 30 & 30 & 30 & 30 & 30 & 30 & 30 \\
\hline & $\mathrm{AC}$ & & & &, $479^{* *}$ & & & &, $551^{* *}$ \\
\hline & $\mathrm{C}$ & & & & & &, $320^{*}$ & &, $570^{* *}$ \\
\hline & $\mathrm{SC}$ & & ,479** & & & & & &, $560^{* *}$ \\
\hline & MP & & & & & & & & \\
\hline & $\mathrm{M}$ & & &, $320^{*}$ & & & & &, $490^{* *}$ \\
\hline & TE & & & & & & & &, $429^{* *}$ \\
\hline
\end{tabular}

*. Correlation is significant at the 0.05 level (1-tailed) ${ }^{* *}$. Correlation is significant at the 0.01 level (1-tailed).

In males group (table. 3) significant correlations are between males all psychological skills average scores mean and self-confidence $r=, 560^{* *}$; concentration $\mathrm{r}=, 570^{* *}$; anxiety control $\mathrm{r}=, 551^{* *}$.
Significant correlation is between such skills as anxiety and self-confidence $r=, 479^{* *}$ and between motivation and concentration $r=, 320^{*}$. 
Table 5. Correlations between the primary scales average scores for females

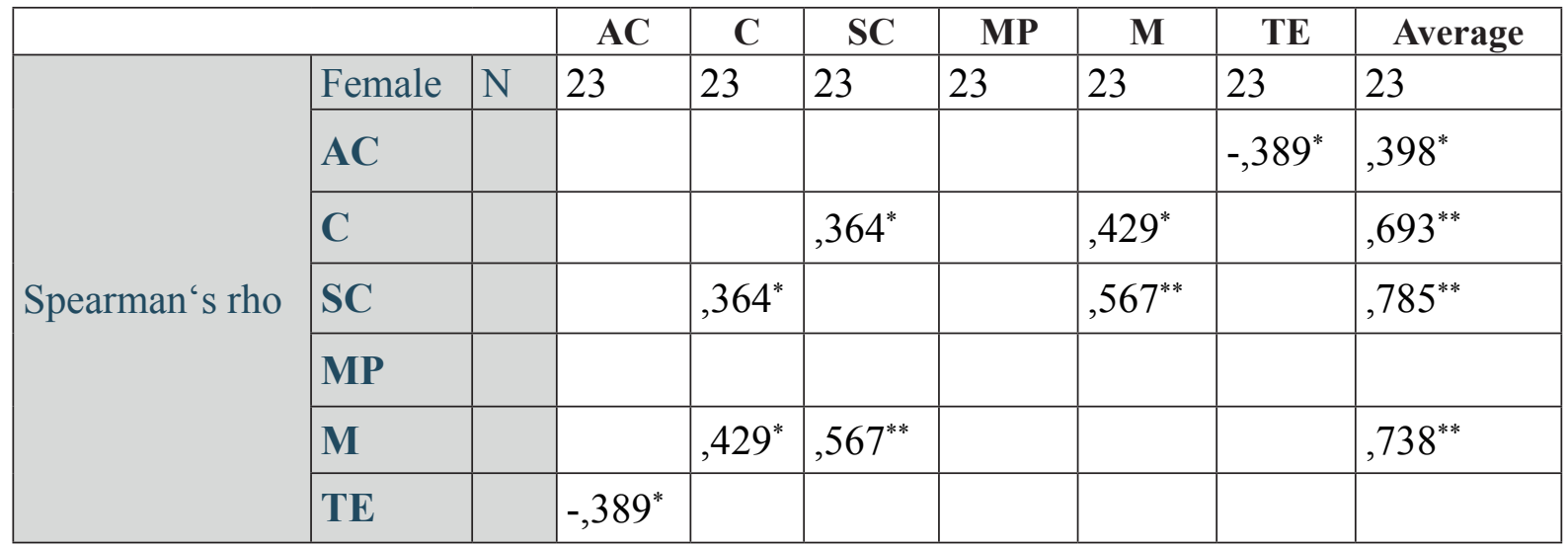

*. Correlation is significant at the 0.05 level (1-tailed).

**. Correlation is significant at the 0.01 level (1-tailed).

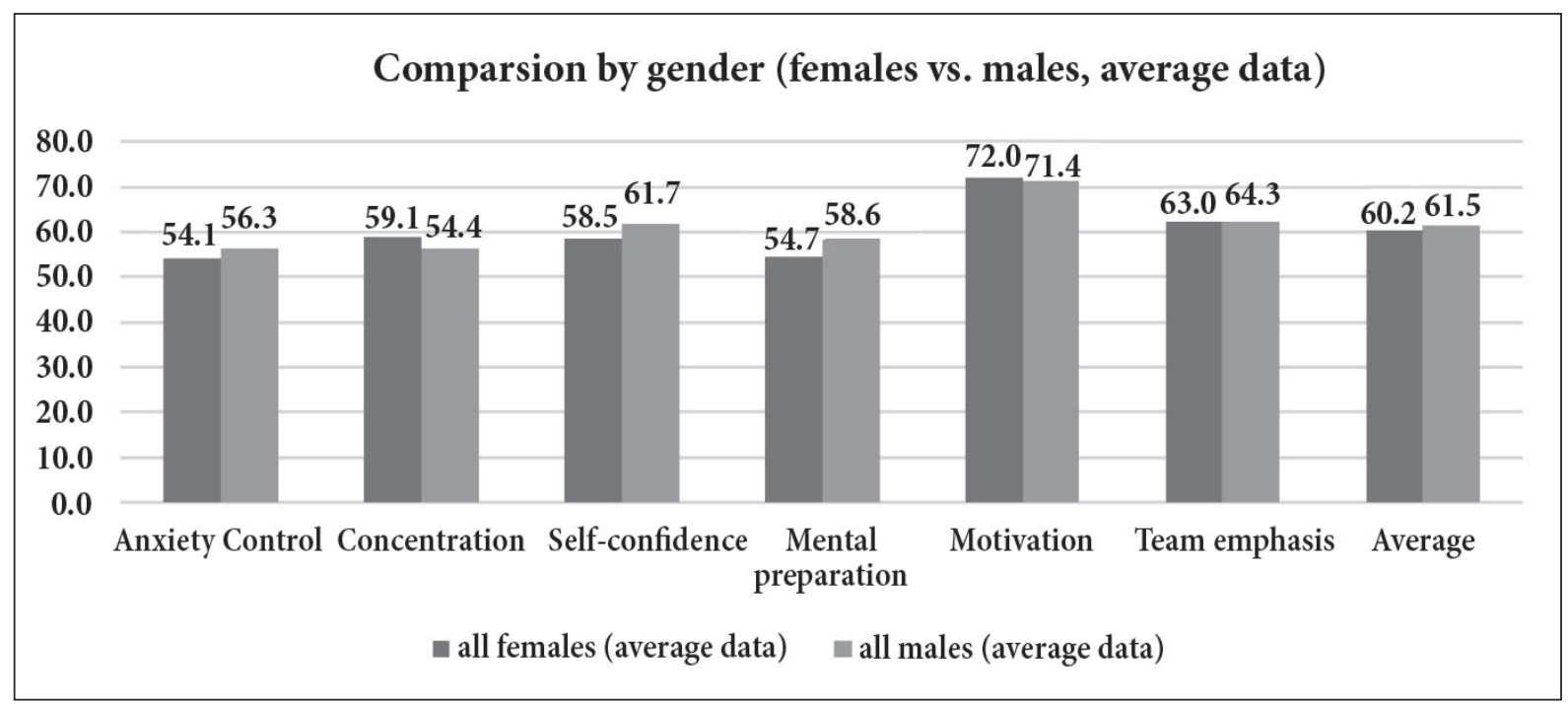

Figure 1. Mean scores of psychological skills for females and males

Figure1 summarizes the average scores for each of the scale in PSIS R5 that measure main psyhological skills and summary average scores for females and males groups. The PSIS R5 results showed that the strongest psychological skills are motivation and team emphasis for both groups. Males showed scores uped average scores in 3 Psychological skills motivation, team emphasis, self -confidence, but females in 2: motivation and team emphasis.

Males showed the highest summary average scores 61,5 , females showed 60,2 scores. There are relatively small differences in results. And it is more interesting to analyzed skills mean results differences by gender in each psychological skill. The highest scores have shown in motivation (72 scores for females and 71,4 for males). It is connected with Ericsson et al. (1993) connclusions: only those who are committed to their sport can persist in deliberate practice. Therefore athletes have to be hightly motivated if they are to have a chance of becoming elite athletes. In this study this scores confirms that young athletes have a high desire to achieve high results and become an elite athletes. Many of athletes who take part in this study have first successful results in World level competitions and have great desire to do it again.

Team emphasis have the second highest scores 64,3 for males and 63,0 scores for females. All athletes are form individual sports. In this case team is group of athletes who together participate competitions. Or peers and team members in clubs or sport centre.

The weakest skill for males and female is anxiety 
control 56,3 and 54,1 score. Most of this athletes are young with less expierence and need improve their preparedness and readness to participate in highest level competitions and reduce the anxiety that accompanies they in competitions. Relaxation is more widely recognized technique that can be used to reduce anxiety in sports. For males the lowest scores are in concentration skill scale 56,4 scores but in females group the lowest scores are in mental preparation 54,7scores. This results showed main improvement areas for each group. The bigest difference in scores is in mental preparation skills - when difference between females and males in scores is 3,9 and in self- confedence skills difference is 3,2 scores. In other scales differences are lower 2,2 scores in anxiety control skills, concentration skills 2,8; team emphasis 1,3 and in motivation skills 0,6 scores.

Females have absolutely highest (in motivation scale 72 scores) and absolutely lowest (anxiety control skills 54,1 scores) scores if compere all showed results for both groups. The high variability of the results indicates the presence of different levels of psychological skills. Some are powerful while others require optimization. This fact is important if athletes think about career development in highest level. Low scores in mental preparation and anxiety control can significantly impact future success. It means that it is a point of application of force in the development of psychological skills.

For males difference between highest scores 71,4 in motivation skills and lowest results 56,3 in anxiety control scale is 15,1 scores which is lower than females have.

They are mainly young athletes and assessing the level of psychological skills are essential for successful career. Accurate psychological skills diagnosis facilitates the development of an appropriate and targeted training plan and programs for athletes groups and individuals. I believe that for young elite athletes, extra work on their psychological development is a must-have for a successful long-term career.

\section{DISCUSSION}

PSIS R5 questionnaire is a suitable tool for diagnosing athletes basic psychological skills. Firstly interest of this study was to find out gender specific characteristics, and then give recommendations for psychological skills training programs preparation for the athlete with aim to improve their mental toughness and psychological skills especialy, for example the ability to relax under great pressure, and the ability to concentrate. The mean scores of all psychological skills haven't significant differences between males and females, however, in order to refine the results, the results in each psychological skill must be evaluated separately for each gender.

The study results showed that the strongest skills are motivation and team emphasis for both of groups, but males have additional strong psychological skill - self-confidence.

As we know from the Dutch researchers discoveries that for discrimination of elite athletes and subelite young athletes motivation and mental preparation were useful indicator that are independent of gender and type of sport. In this study the motivation skills are the strongest skills for both males and females, but mental preparation no.

Main results showed in this study are connected with results discovered by Mahoney (1998). He has found that elite athletes have clear goals for each day, less anxiety, greater self-esteem, higher motivation and better control strategies. The similarities in this study with Mahoneys M. J. conclusions are in two skills motivation and self-confidence which are strongest caracteristics for talanted males athletes in Latvia, too. The differences occurred in several studies results. The main improvement areas have been identified in ths study are anxiety control, concentration and mental preparation for all athletes and additional for females self-confidence is weak skill, too.

Not only physical and tactical preparation, but also psychological preparation, which involves the development and training of psychological skills, is essential for a successful athlete's career.This study findings can be used as a starting point for developing well-targeted psychological skills training programs for talented athletes.

\section{REFERENCES}

Aoyagi, M.W., \& Portenga S.T. The Role of positiveethics and virtues in the context of sport and performance psychology service delivery. (2010). Professional Psychology: Researche and practice, 41(3),253-259.

Deci E.L., Ryan R.M. (2000). The "What"and "Whay"of 
Goal Pursuits: Human Needs and Self Detremination of Kreiner-Phillips, K., Orlick, T. (2005). Winning After Behavior Psyhological Inqury, 11,4, pp.227-268. Winning: The Psychology of Ongoing Excellence. UniverEricsson, K.A., Krampe, R.T., and Tesch -Rōmer, C. sity of Ottawa.

(1993). The role of deliberate practice in the acquisition of expert performance. Psychological review, 100, pp. 363-406.

Mahoney, M.J., Gabriel, T.J., Perkins, T.S. (1987). Psychological skills and expectional athletics performances. The Sport Psychologist. 1, pp. 181-199

Fernāte A. (2008). “Transdisciplināra pieeja ķermeniskās izpratnes izpētē" Nozaru pedagog̣ija - sporta psihologijia. Promocijas darbs, Rìga.

Mahoney, M.J. (1988). Psychological skills Inventory for Sport (R5) (5th ed.) Goleta,CA:Health Science Systems,

Elferink-Gemser, M. T.. (2005). Today's talented youth field hockey players, the stars of tomorrow? a study s.n. Link to publication in University of Groningen/UMCG Sindik, J., Novokmet, N., Havaš-Auguštin, D. (2013). The Application of psyhological skills inventory for sports at research database Citation for published version (APA). Croatian coaches and recreational table tennis players. Sports Science 6. 1:54-60 